\title{
Mediación Familiar en México. Avances en Justicia alternativa para conflictos familiares ${ }^{1}$
}

Family Mediation in Mexico. Advances in alternative justice for family conflicts

\author{
Araceli, Castillo Caraveo ${ }^{2}$ \\ (Dhttps://orcid.org/0000-0003-0826-0723 \\ Universidad Autónoma de Guadalajara, México \\ do) $\mathrm{https}: / /$ doi.org/10.29105/pgc7.13-5
}

\section{RESUMEN}

El presente artículo es resultado de una revisión que tuvo por objetivo analizar el desarrollo de la mediación dirigida a las entidades federativas y su impulso en la mediación familiar, así como los avances que estas han tenido respecto a los desarrollos de este proceso de justicia alternativa a nivel nacional, por lo que para hacer propuestas en la materia, se necesita indagar respecto a cómo se encuentra este proceso alternativo en la actualidad y de qué manera la contemplan actualmente, desde sus legislaciones especializadas hasta los números de asuntos que han resuelto en el último año, de modo que, se analizará conforme a las estadísticas y las legislaciones, aquellos avances que han tenido en la mediación familia.

Palabras claves: Conflicto familiar, familia, mediación, mediador, principios.

\section{ABSTRACT}

This article is the result of a review that aimed to analyze the development of mediation aimed at federal entities and their momentum in family mediation, as well as the progress they have made with regard to the developments of this alternative justice process at the national level, so to make proposals in this area, it is necessary to look into how this alternative process is currently and how it is currently contemplated, from its specialized laws to the numbers of issues that have been resolved in the last year, so that, it will be analyzed in accordance with the statistics and legislations, those advances that have had in family mediation.

Keywords: Family, family conflict, mediation, mediator, principles.

Recibido: 04 de Mayo 2020 - Aceptado: 29 de Julio 2020

Cómo referenciar este artículo:

Castillo, C., A. (2021). Mediación Familiar en México. Avances en Justicia alternativa para conflictos familiares. Revista Politica Globalidad y Ciudadanía, 119-149. Recuperado de http://revpoliticas. uanl.mx/index.php/RPGyC/article/view/170. https://doi.org/10.29105/pgc7.13-5

\footnotetext{
1 Este artículo es producto del proyecto Mediaciòn familiar, financiado por la especialidad en derecho civil en la Universidad Autònoma de Guadalajara. Iniciado en Septiembre de 2020 y finalizado en Diciembre de 2020.

2 Maestrante en Derecho Procesal Civil y Mercantil por la Universidad Autónoma de Guadalajara Campus Tabasco, Código Orcid: 0000-00030826-0723. Email: araceli.cast86@gmail.com.
} 


\section{1.- INTRODUCCION}

El presente trabajo tiene como objetivo llevar a cabo estudio cualitativo sobre los avances que ha tenido la mediación familiar en México, dado que este mecanismo alterno de solución de controversias es un método especializado que ayuda a solucionar los conflictos familiares de diversa índole y fue uno de los primeros en impulsar la resolución de las controversias sobre esta materia en México sin necesidad de llegar a las instancias judiciales. En ese sentido, se llevará a cabo un estudio partiendo de lo que son los conflictos familiares y como se clasifican, así como las opiniones de diversos doctrinarios especialistas en la materia, lo que dará un panorama claro de que son las controversias y la manera en cómo se pueden resolver.

Seguidamente, se estudiarán los conceptos de mediación familiar, así como los principios que rigen estos procedimientos, tal como la confidencialidad, la igualdad, la imparcialidad, entre otras directrices clásicas de la mediación. Posteriormente, se podrá estudiarán los avances que la mediación familiar ha tenido a nivel nacional, así como la investigación que se haga de acuerdo con las estadísticas que el Instituto Nacional de Estadística y Geografía ha hecho respecto al tema.

Actualmente, en México, hay estados que no contemplan en sus legislaciones expresamente el mecanismo alterno de solución de conflictos con especialización en materia familiar, o bien hay entidades federativas que todavía no cuentan con mediadores especializados en la especialidad, o bien, órganos encargados específicamente de resolver conflictos alternos relacionados con familia, por lo tanto el objetivo principal de este trabajo es saber que estados lo contemplan y de qué manera lo expresan en sus legislaciones asimismo como se ha avanzado en la resolución de conflictos familiares a nivel nacional y cuantos son los asuntos que han terminado en convenio a través de una mediación.

Sin embargo, cabe señalar la siguiente pregunta ¿cuáles son los avances que se ha hecho respecto a la mediación familiar a nivel nacional? En ese sentido, la mediación familiar empezó como un mecanismo alterno de solución de contro- 
versias iniciado en entidades federativas como en el Distrito Federal (hoy Ciudad de México), de modo que, se necesita saber cuál es la situación de las entidades federativas respecto a la implementación de estos mecanismos.

\section{2.-FUNDAMENTO TEÓRICO}

\section{Los conflictos familiares}

Los conflictos o controversias han existido desde tiempos de antaño, ya que en las guerras hasta en los conflictos más comunes entre las personas, han sido la fuente de diferentes problemas que traen aparejado desastrosas consecuencias en el entorno social, económico y en diferentes aristas de la convivencia, sin embargo, al originarse un conflicto, también se necesitan herramientas que ayuden a resolverlo, por lo que estos instrumentos deben ser utilizados de forma correcta y tener los conocimientos necesarios que ayuden a ejecutarlos en los términos que establecen las reglas o principios que rigen estas modalidades de solución de controversias.

En ese sentido, el conflicto ha sido definido dentro de la doctrina especializada de diferentes maneras, así, un concepto comúnmente aceptado desde el latín, es la palabra conflictus que significa chocar, afligir o infligir, ya que tal como María Elina Funquen Alvarado (2003) señala el conflicto también significa desgracia, mala suerte, lo que puede también considerarse como algo aberrante o patológico, violencia, disfunción en general, o bien como una situación no animada para las personas que se encuentran inmiscuidas en él.

La acepción original del conflicto da una idea de un choque, de una disfunción en algún entorno, lo que puede suscitarse dentro de diferentes entornos sociales, esa mala desgracia o mala suerte que hace referencia la autora, puede ser una situación que se genera a partir del desacuerdo que se suscita entre una o varias personas, o bien puede ser una consecuencia para algunas personas inmersas en el conflicto.

Por lo tanto, dentro del entorno social se pueden originar estas situaciones anímicas que ocasionan molestias e incluso llegan a extremos como la violencia física 
$\mathrm{u}$ otros tipos de violencia. De igual manera, es evidente que, si las controversias se originan en la sociedad, estas también se introducen hasta su base que es la familia. Así tal como, Martínez (2019) menciona, la familia es el origen de todas las relaciones sociales, definido como un grupo, un núcleo o célula de la sociedad que se compone por distintos individuos de forma indisoluble, en ese tenor, se puede considerar a la familia como una unidad social, plural y compleja y no solo como una simple unidad o individualidad.

Cabe señalar que el origen de la familia es indisolublemente la base de la sociedad, es la que siembra las semillas para que las relaciones sociales se vayan forman y originando, formando una unidad plural y compleja como señala la autora, ya sea en una determinada situación geográfica, en un estado, en un país, o en un pueblo o villa pequeña, de modo que cuando estas conviven e interactúan entre ellos, se empiezan a crear las relaciones sociales,

Por lo tanto, dentro de la familia hay un número incierto de individuos que forman una unidad y están unidos no solo por vínculos de afinidad, o consanguíneos, además, se encuentran los de tipo afectivo o emocional, y estos nexos son los que más unen a estos grupos, no obstante, se pueden presentar ocasiones en que a pesar de las relaciones entre ellos, empiezan a verse deterioradas por diversas causas, que van desde los desacuerdos en una herencia, un conflicto por divorcio, o hasta el extremo de llegar a una violencia intrafamiliar, de modo que esto genera un caos en la estabilidad del núcleo social y puede traer desastrosas consecuencias desconfigurando las estabilidades de otros núcleos sociales.

En ese sentido, cuando se habla del tema sobre conflictos familiares, la doctrina especializada ha elaborado la tipología de estos, así, Iglesias (2018) menciona que los conflictos familiares se clasifican de la siguiente forma: Conflictos de Convivencia: este tipo de controversias se originan en la interacción de los diferentes miembros del círculo familiar, de modo que, dentro de este tipo se pueden subclasificar en conflictos intergeneracionales que se da entre padres e hijos causada por diferencias entre los valores y características de cada generación. Asimismo, se puede hablar de conflictos que surgen por la convivencia de personas que integran 
el componente familiar, tales como comunicación, respeto, reparto de tareas.

Cabe señalar que los conflictos de convivencias y los conflictos de personas que integran el componente familiar se dan entre tíos, sobrinos, primos, es decir puede variar los roles de los participantes en la familia, de forma que, los participantes pueden ser en línea recta o colateral hasta el cuarto grado o más grados, siempre las controversias de este tipo se pueden originar entre familias lejanas o cercanas.

Por otro lado, se encuentran los conflictos económicos familiares, que tratan del reparto de bienes o sostenimiento del hogar por parte de los miembros de la unidad familiar, este tipo de controversias abarcan la distribución de funciones y actividades, así como el reconocimiento y el valor que se otorga a cada integrante de la familia para el sustento del hogar (Iglesias, 2018, p.86).

En ese orden de ideas, los conflictos económicos familiares tienen una peculiaridad muy importante, dado que la controversia está en el valor pecuniario, por lo tanto, pueden suscitarse casos en los cuales un miembro de la familia no aporte a los gastos del hogar donde el caso más común se presenta hipotéticamente cuando la madre o el padre no aportan a los gastos para los hijos o el sostenimiento para los gastos de la casa. Sin embargo, los casos de esta clasificación se reflejan en padres separados o excónyuges, donde alguno no quiere aportar a los gastos de los hijos cuando se trata de pensiones alimenticias o pensiones compensatorias, lo que sin duda alguna trae consigo conflictos que se pueden ir agravando conforme al tiempo.

Por otro parte, se encuentran los conflictos de las familias reconstituidas, que son los que se crean a partir de la aparición de otros cónyuges, y otras aportaciones familiares como hijos de la nueva pareja, familia extensa, etcétera. De modo que, este tipo de conflictos se origina en las relaciones de nuevas parejas o bien entre los hijos de la primera pareja con la segunda cónyuge, empero, los conflictos pueden tener detrás de ellos diversos intereses o necesidades, uno de ellos puede ser que haya una molestia o no haya simpatía entre los mismas parejas, o bien, los hijos de la expareja con los de la segunda no tengan una buena relación, por lo 
tanto va a depender del ambiente que reina y los antecedentes que se encuentren en ese tipo de relaciones.

Por último, se encuentran los conflictos entre las familias acogedora y biológica, las cuales tienen contacto y convivencia, así, estos hechos producen nuevas necesidades y situaciones complejas que precisan mecanismos positivos, pacíficos e inclusivos para favorecer la resolución eficaz. (Iglesias, 2018, p.86)

Por ende, dentro de la vida diaria se pueden originar conflictos familiares en sus diferentes modalidades, por lo que se debe contar con herramientas especializadas que ayuden a resolverlos sin la necesidad de llegar a instancias que agraven las relaciones familiares y los afectos que entre ellos existen. En ese sentido, los desacuerdos representan una serie de obstáculos que impiden la convivencia entre ese grupo, de manera que es necesario aprender a controlarlos y transformarlos a través de la mediación familiar.

En ese orden de ideas como Ponce (2017) menciona la crisis familiar es parte del proceso conflictivo-evolutivo que se vive como seres humanos y grupos sociales, sin embargo, lo que verdaderamente importa es rescatar de esta etapa de crisis, la experiencia, resaltar lo positivo, y el replanteamiento de cada vida personal ó social sin desviarse de la plenitud y la paz.

En efecto, lo que el autor ha mencionado como crisis familiar, es verdaderamente un proceso conflictivo evolutivo, donde de las experiencias familiares pueden ser reflejo para que aprendan a convivir. Por lo tanto, para vivir esas experiencias y conocer cómo se originan este tipo de conflictos, es necesario adentrarse en las técnicas y herramientas que ofrecen los mecanismos alternos de solución de controversias, en especial, en su vertiente familiar.

\section{La Mediación Familiar}

Tal Como Rodríguez (2010) menciona, la mediación familiar se configura dentro de un nuevo paradigma para la resolución de conflictos familiares, o bien, como una alternativa al sistema judicial adversarial o contradictorio ya que estos últi- 
mos lejos de resolver los conflictos, contribuyen a agravarlos de forma cuantitativa y cualitativa aquellos procesos de crisis y ruptura familiar (p.103). De manera que, como Pérez (2008) señala la mediación es:

Una estrategia de intervención que tiene como fin conseguir una salida pacífica a los conflictos generados en la convivencia familiar. En este proceso, las partes en disputa pretenden resolver sus diferencias negociando con la ayuda de una tercera persona, el mediador, quien facilita la búsqueda de soluciones, permaneciendo neutral y sin ejercer ningún tipo de poder en las decisiones que se adoptan. (p.940)

En efecto, la mediación es un mecanismo alterno de solución de controversias donde participan dos o más partes y un mediador, quien es experto en usar técnicas y herramientas para transformar su conflicto familiar, por lo que estas de forma voluntaria someten su conflicto ante un experto, quien puede estar especializado y tener experiencia en el trabajo de diferentes conflictos familiares, como el caso de los cónyuges separados o bien, un grupo familiar que acuda de manera voluntaria a las sesiones que se brindan y puedan llegar a un acuerdo.

En ese sentido, más específico es el concepto de Perrone (1999) quien define a la mediación familiar como una forma de ayudar en la gestión de conflictos y no precisamente en su resolución, en el que las partes son los padres que se separan y son orientados por terceros no implicados en el proceso conflictivo, asimismo colaborarán con las partes en la manera de buscar soluciones para los hijos, garantizando las responsabilidades parentales hasta finalizar el proceso ya sea con un acuerdo escrito el cual que debe ser homologado por el juez.

No obstante, debe de tomarse en consideración, que la mediación no solo es un mecanismo que ayuda a llegar a un acuerdo, dado que más allá de esto, su objetivo principal es mejorar las relaciones rígidas que se originaron a partir del enfrentamiento que hubo entre las partes, de manera que, con las técnicas como el rapport, la escucha activa entre otras se ayuda a que estas puedan encontrar una mejor manera de resolver sus diferencias y volver a tener una buena convivencia. 
Así Valdivia (2019) menciona que la mediación familiar propicia el diálogo, la comprensión de las situaciones problemáticas, la madurez para anteponer los intereses colectivos sobre los intereses individuales asimismo genera un ambiente propicio para compartir y debatir ideas, así como propuestas que brinden confianza y que de igual forma permitan avanzar en la construcción de acuerdos y consensos.

Por lo tanto, el rol del mediador se centra en las necesidades del sistema familiar, en cuanto promueve el ejercicio de los nuevos roles paterno-filiales, enfocando su interés en las necesidades de los padres e hijos, así, la mediación familiar representa una nueva visión de resolver los conflictos conyugales, y sus diferencias de una manera más humana en donde se revisará que el acuerdo celebrado por los mediados tenga el objetivo de ser factible para cumplimiento y duradero en el tiempo debido al factor temporal de la familia y su esencia. (González, 2020, p.77)

No obstante, como Iglesias (2018) comenta el método habitual de los conflictos familiares es el sistema judicial, pero este sistema es un elemento que no está preparado para hacer resolución frente a determinados conflictos familiares, es decir:

La discrepancia entre el conflicto surgido en el seno familiar y el instrumento que se utiliza para su gestión, mayoritariamente y como hemos visto anteriormente el Sistema Judicial, se presenta de muy diversas formas, siendo las más significativas una agudización del conflicto interpersonal de los adultos, un deterioro o ruptura de las relaciones parentales y una serie de incumplimientos de las medidas determinadas en la sentencia judicial. (p.82)

Además, el sistema judicial no ha traído beneficios para la mejor convivencia de las familias, ya que en la práctica por ejemplo se puede notar como los padres de un hijo después de una separación no llevan una buena convivencia, asimismo los procedimientos jurisdiccionales traen aparejados gastos exorbitantes como los honorarios de los abogados, los gastos en gestión, entre otros.

Sin embargo, la mediación familiar puede presentar diversas modalidades, ya que 
por un lado en la mayoría de las entidades federativas se encuentran establecidas dentro de los poderes judiciales locales o bien, se encuentran instituciones privadas consideradas como especialistas en este tipo de conflictos (mediadores privados), o bien bufetes legales donde los abogados empiezan a especializarse en esta materia.

En ese sentido, Gorjón y Vázquez (2015) mencionan que la mediación permite el mejoramiento de las instancias judiciales y surge como un nuevo paradigma para contrarrestar los aspectos, ya que en la última década han influido para lo que se ha denominado una crisis de justicia. Este mismo autor menciona un listado de las deficiencias en la resolución de los conflictos en el sistema judicial y la necesidad de la mediación debido a: a) las instancias judiciales no se dan abasto; b) difícil acceso a la justicia; c) ignorancia y escaso conocimiento de los MASC; d) desconocimiento del rol de los abogados en la mediación; e) perspectiva de los demás profesionales.

Cabe destacar que Gorjón se refiere a un elemento que considera como uno de los principales obstáculos para que no se desarrolle como el desconocimiento de los MASC y el desconocimiento del rol de los abogados en la mediación, a decir verdad muchos abogados vienen de la práctica del litigio donde sus casos los resuelven a través de juicios que se les presentan, de igual manera, los estudiantes pertenecientes a las facultades de leyes se integran en la práctica de lo que es el litigio, y los MASC los dejan como un procedimiento secundario, sin darle la debida importancia que tienen hoy en día.

Sin embargo, debe considerarse que poco a poco los mecanismos alternos han venido integrándose de una manera paulatina en diversas ramas del derecho, aunque en algunas materias no se encuentre integrada en la ley de la materia, como es el caso del derecho administrativo, de modo que a través de los talleres o conferencias que se imparten han tenido repercusión muy importante en la práctica jurídica, hasta el punto de despertar ese interés en los abogados y los estudiantes de derecho. 
En ese orden de ideas, debe considerarse que este no es solo un procedimiento dirigido a todo aquel que tenga una formación jurídica, ya que de igual manera los psicólogos o trabajadores sociales son los perfiles que se necesitan para ocupar puestos en la mediación, dado que en un momento estos pueden tener un mejor talento que los abogados para poder desarrollar la justicia alternativa en cualquier materia, o bien pueden tener más experiencia dentro de la praxis para métodos de solución de conflictos.

Por lo tanto, la mediación familiar a partir de lo que se comentó anteriormente, puede dividirse en judicial e intrajudicial, ya que, -de acuerdo con la doctrina-, la de tipo intrajudicial es aquella que tiene lugar en el marco de un proceso judicial a requerimiento de ambas partes, de una de ellas, o bien, por indicación del juez. Por su parte, la mediación extrajudicial es impulsada antes de iniciar el proceso de jurisdicción.

Si bien es cierto, los mecanismos alternos no solamente pueden darse en los órganos que se encuentran adscritos a los Tribunales Superiores de Justicia de las entidades federativas, de manera que, hoy en día existen despachos o buffettes legales que ya cuentan con una preparación o certificación para poder llevar a cabo lo que se conoce como una mediación privada, teniendo sus respectivos costos, y especialización en conciliación o mediación familiar. Por lo tanto, una de las ventajas es que muchos abogados prefieren resolver sus conflictos a través de los mecanismos alternos, debido a la rápida solución que se le da a los asuntos, y no se debe dejar de la lado el nacimiento de una buena relación que puede generar entre las partes al resolverse.

Por un lado, Ortuño (2000) considera que la mediación intrajudicial es aquella que se desenvuelve dentro del ámbito de gestión de litigio en los tribunales, en cambio la de carácter extrajudicial es la que tiene lugar fuera del ámbito del proceso y sin alguna interferencia en el mismo, ya sea a la interposición de la demanda, o con posterioridad a la misma.

Como se refleja, la mediación puede ser solicitada en cualquier momento por las 
partes ya sea durante el procedimiento o bien, antes de instaurarlo, de manera que, en la mayoría de las legislaciones de las entidades federativas se encuentran las condiciones por las cuales pueden someterse a los procedimientos de mecanismos alternos. Actualmente, en la mayoría de los poderes judiciales del fuero común, se les hace saber a las partes en los primeros acuerdos de admisión de demanda el hecho de que en todo momento tienen el derecho de acceder a los mecanismos alternos de solución de controversias, por lo que sí es su deseo el juez o secretario judicial los puede canalizar al área de conciliación o mediación en el momento en el cual lo requieran.

\section{Los principios en la mediación}

En todos los mecanismos alternos de solución de controversias hay principios que se deben garantizar para el buen desarrollo de estos procedimientos, así al salvaguardarse y respetarse estas directrices, la mediación o conciliación van encaminadas a tener éxito en la transformación de la controversia, por lo tanto, para saber cómo se desarrollan, es sumamente importante mencionar cada uno.

Por un lado, se encuentra el principio de voluntariedad, que como Conforti (2018) señala, las personas físicas o jurídicas que participen en un proceso de mediación lo harán de manera voluntaria, tanto al inicio, como en la continuidad, y finalización del proceso el cual va a depender exclusivamente de la voluntad de las partes. En efecto, las partes al acudir a estos mecanismos tienen que considerar que lo están haciendo de manera voluntaria, por lo tanto, el acuerdo debe ser mutuo para poder someter su conflicto y transformarlo con la ayuda de un profesional.

El profesional de la mediación o cualquier servidor público de alguna institución debe considerar que las partes siempre tienen la opción de poder acudir a algunos de los mecanismos alternos que oferta la ley, no obstante, para que esto suceda los funcionarios y los servidores públicos de algún órgano e institución deben estar preparados o capacitados para explicarles a las partes en qué consisten los mecanismos alternos de solución de controversias, y que de manera voluntaria pueden acudir a ellos, sin la necesidad de caer en lo que Gorjón menciona como 
un desconocimiento de los MASC.

Cabe señalar que no necesariamente los mediadores o los conciliadores son los únicos que tienen que hacerle saber a las partes lo que es el mecanismo, ya que de igual manera este conocimiento lo deben tener todos los servidores públicos, con la finalidad de hacerle saber a las partes que de manera voluntaria pueden acudir a un profesional que los ayude a resolver su disputa sin necesidad de llegar a otras instancias que lamentablemente van a agravando la situación en un futuro.

Asimismo, se encuentra el principio de neutralidad, ya que tal como Conforti (2018) menciona, todos los actos dentro de la mediación se desarrollarán de manera que permitan a las partes por sí mismas lograr un acuerdo.

En ese orden de ideas, el experto en mediación facilitará la comunicación entre las partes y garantizará la disposición de la información y el asesoramiento suficiente. Sin embargo, debe considerarse que cuando ocurran hechos que afecten la imparcialidad del mediador, este no podrá iniciar o bien, deberá abandonar la mediación en cualquier momento. De modo que, esas circunstancias pueden ser: a) todo tipo de relación personal, contractual o empresarial con alguna de las partes, b) intereses directos o indirectos en el resultado de la mediación; c) el mediador o miembro de una empresa u organización que hayan actuado anteriormente a favor de una de las partes en cualquier circunstancia, con excepción de la mediación.

Por lo tanto, en una mediación o conciliación, el mediador no debe tener intereses ya que se rompen los objetivos de los mecanismos, además, la ética de este profesional se ve corrompida y puede llevar al fracaso del acuerdo entre las partes. Sin embargo, dentro de la selección de candidatos que aspiran a ocupar estos cargos dentro de las instituciones oficiales o en el poder judicial, tienen que pasar por una evaluación donde se les detecta que tan capaces son para el cargo, asimismo deben acreditar el control de confianza para medir si el candidato es un sujeto imparcial, entre otro tipo de evaluaciones que se aplican en estos exámenes.

Por otro lado, se encuentra el principio de confidencialidad, que como Conforti (2018) comenta, este se extiende hasta el mediador, es decir, está protegido por 
el secreto profesional, abarcando a las instituciones de mediación y las partes intervinientes quienes no podrán revelar la información que obtengan derivada del procedimiento. Por lo tanto, la confidencialidad establece que los mediadores o las partes que participen en el procedimiento están obligados a declarar o aportar documentación en un procedimiento judicial, acerca de la información y documentación que deriva de un procedimiento alternativo de justicia.

En ese sentido, la confidencialidad trae consigo muchas consecuencias, ya que al revelarse la información que las partes hacen saber al mediador, este puede incurrir en una responsabilidad administrativa hasta suspenderlo de su cargo y quitarle la respectiva licencia o certificación que lo legitima como un profesional en la mediación. Por lo tanto, debe considerarse el documento que firman las partes al signarlo, con la precaución de que no se revele por ningún motivo, lo que se toca dentro de la mediación, ya que así se cuenta con la seguridad de poner penalizarlo en caso de que la información que se revele sea objeto de una sanción.

Sin embargo, hay excepciones cuando se debe dejar de lado la reserva en estos procedimientos, así Conforti (2018) advierte que cuando las partes han expresado su consentimiento de que el procedimiento no sea confidencial, o bien, cuando por resolución judicial los jueces de la jurisdicción penal lo soliciten.

Por tal motivo, se pueden presentar ocasiones en que las partes implicadas hayan sido sujetos del delito de mayor gravedad de los que - en el caso de la mediación penal- la mediación en su respectiva la ley no tenga contemplados para poder resolverse a través de los mecanismos alternos de solución de controversias. De igual manera, se puede presentar el caso en el que los sujetos que fueron o son partes de la mediación o bien, están bajo la investigación o procesamiento de un delito, por lo que el juez de la jurisdicción correspondiente solicitará a los órganos de mediación, rendir los informes de lo que sucede con una o todas las partes que están implicadas en la mediación.

No obstante, Gorjón (2017) menciona los rasgos característicos de confidencialidad en una mediación, así para el mencionado autor las características son las 
siguientes: a) preservar la imagen de las partes dado que esto les proporciona una libertad y repele el efecto de la estigmatización en determinados conflictos, b) se garantiza la legal protección de la información, ya que este es un deber de custodia de los mediadores y de las partes en el proceso; c) genera reciprocidad ya que es una obligación para ambas partes, donde el incumplimiento daría un efecto negativo en el acuerdo que pretenden hacer; d) asimismo, es un procedimiento abreviado que garantiza el acceso a un número determinado de personas, protegiendo la información; e) es un procedimiento discreto, que evita los efectos sociales o económicos respecto de una empresa o de una persona, donde determinado número de personas puede tener acceso a la información; d) el proceso garantiza quien o quienes pueden tener acceso a determinada información; e) la obligación legal alcanza a determinadas profesiones con sus clientes como son los médicos o abogados, asimismo, el secreto profesional no debe usarse con fines personales; f) se origina una buena comunicación y apertura de las partes, en virtud de que la medición de calidad, otorga la seguridad para que las partes puedan mostrar sus verdaderos intereses: g) implica compromiso de reserva sobre determinadas circunstancias, h) se le considera como un puente de confianza entre el mediador para lograr la solución del conflicto.

Por un lado, Gorjón enfatiza bien lo que es la estigmatización, es interesante saber que un proceso de mediación, las partes pueden tener la seguridad de que su información revelada no será dada a conocer por ningún motivo, ya que esta puede traer consigo información comprometedora o vergonzosa, lo que caería en un estigma o prejuicios por parte de la sociedad. Es muy común que los medios de comunicación tengan acceso a juicios de personalidades públicas, o bien el número de juicios que por ley deben estar publicados en sus respectivas páginas de Internet, lo que trae consigo también el nombre de las partes - a excepción de la información sobre menores de edad- así como los tipos de juicios en que las personas están implicadas. Por lo tanto, al estar información en sus manos, son expuestas a la opinión pública, lo que puede traer estigmatizaciones por parte de los mismos. 
Sin embargo, la mediación permite tener un círculo cerrado donde solo las partes pueden estar implicadas, la ley es protectora en este sentido, no tiene la obligación de rendir cuentas en los mecanismos alternos de solución de controversias al público, lo que si pasa con los juicios en virtud de la Ley de Transparencia y Acceso a la Información Pública, de manera que, -en virtud del principio de confidencialidad-, las partes tienen la seguridad de que su caso no será expuesto a la opinión pública por ningún servidor público.

En ese sentido, la mediación trae consigo uno de los principios más interesantes que es la confidencialidad, dado que se establece la finalidad de preservar la información delicada que se trata en los procesos de justicia alternativa, asimismo, las partes tienen intereses que no pueden ser revelados fuera de este proceso, dado que se pondrían en riesgo los procesos que se tienen en desarrollo y la confianza que las partes brindan a estos mecanismos alternos de solución de controversias y al profesional en mediación.

Por otro lado, un principio muy conocido es la legalidad, el cual, ya que de acuerdo a Gorjón (2017), la mediación o conciliación se tienen que apegar a lo que dispone la ley, dado que, si un conflicto no se puede mediar, entonces se estaría transgrediendo el orden jurídico, así, para el mencionado autor, este principio da otra idea de los conflictos mediables en el momento de su gestión o transformación, de ahí, la importancia en que se elabore una tipología que establecen las normatividades correspondientes en la materia, variando de tiempo y espacio, así este autor menciona:

Es por ello especialmente importante verificar la lex fori del lugar de la instrumentalización del procedimiento de gestión y trasformación del conflicto, así como del lugar en donde se pretenda ejecutar el acuerdo de mediación o conciliación o el laudo arbitral. (Gorjón, 2017, p.58.)

Asimismo, hay que considerar que en ocasiones los profesionales de la mediación puede ser diversos profesionistas, desde abogados, psicólogos, trabajadores sociales, no obstante, debido a la formación de estos -que no forman parte del gremio 
jurídico en algunos casos-, se puede suscitar el problema del desconocimiento de la ley, lo que sin duda atraería consecuencias para el desarrollo del procedimiento. De manera que, los abogados tienen una amplia ventaja para conocer cómo se clasifican los conflictos, así como la normatividad vigente en el entorno en el cual se encuentran, sin embargo, si un psicólogo o un trabajador social pretenden aspirar a ser un facilitador, tienen la obligación de estudiar la ley que rige la materia, tal es el ejemplo de algunos casos en violencia familiar donde hay estados que prohíben expresamente que un conflicto no se puede someter a una mediación familiar.

Finalmente, se considera otro principio importante de la mediación, que es el principio de equidad, el cual trata de procurar el equilibrio en el momento de tomar las decisiones, por lo que esta directriz es un principio de interpretación según los intereses de las partes (Gorjón, 2017), Así, de acuerdo a De la Rosa (2010), la equidad pretende garantizar la información para que las partes tengan su derecho de seguir o abandonar el procedimiento en cualquier momento y puedan recurrir al sistema judicial o extrajudicial, ya sea cuando estas no estén satisfechas con el resultado o el desarrollo del mismo, y de igual manera se salvaguardan sus derechos, de modo que podrán disponer de un tiempo para decidir si aceptan o no la solución del caso que se proponen para resolver el conflicto.

Este principio que se presenta es sumamente interesante en el momento de la práctica de la mediación, ya que algunas de las partes en un momento no pueden estar de acuerdo con la propuesta que les hace ver el experto, en virtud de que los intereses pueden verse afectados por este tipo de acuerdos. Sin embargo, lo interesante de estos mecanismos alternos es que ofrecen una modalidad de ganar-ganar, es decir, la mediación no pretende que una parte pierda menos que otra, o bien, que una sea más vencedora que la otra, de manera que, con las técnicas y métodos que utilice el experto, se podrá descubrir los intereses o necesidades de las partes, y en base a ellos, podrá darle forma a un acuerdo donde todos ganen, y todos vean satisfechas sus intereses y necesidades, y de igual manera, que mejore la relación entre los mismos. 


\section{La mediación familiar a nivel nacional}

En primer lugar, la mediación en México ha sido un paradigma sumamente novedoso en la forma de solucionar conflictos desde diferentes ámbitos, así en materia penal ha sido un recurso muy efectivo para resolver controversias en las diferentes etapas del sistema de Justicia Penal, así como en la justicia para adolescentes. Sin embargo, la mediación también ha alcanzado otras áreas, pero en el caso de la mediación familiar es uno de los métodos que más demanda tienen en la forma de solucionar conflictos.

Por un lado, en opinión de Gorjón y Steele (2012) mencionan que la mediación familiar siempre ha estado presente en los códigos civiles a través de las audiencias o reuniones de avenencias, donde el juez en turno o el secretario exhortan a que las partes lleguen a un arreglo, de igual manera, pasa con los hijos, en el caso de los alimentos, etcétera, de modo que las partes se ponen de acuerdo y el juez sanciona.

En efecto, es común que en la práctica, aún antes de que se conociera la mediación familiar como un mecanismo alterno, los secretarios judiciales siempre tuvieran esa facultad junto con el juez de proponer un arreglo para las partes, sin embargo, hoy en día existe lo que es el divorcio incausado, donde ya con más facilidad un cónyuge puede solicitar el divorcio sin necesidad del consentimiento de la otra parte, sin embargo aunque la ley permite evitar el conflicto por un lado, hay casos donde están de por medio los hijos, o bien los bienes, de manera que el conflicto se hace presente, y es ahí donde pueden entrar las habilidades del secretario para poder canalizarlos al área correspondiente y llegar a un convenio a través de la mediación.

Antes los jueces o secretarios podían hacerles saber a las partes en la audiencia si les apetecía llegar a un arreglo enfocado en los hijos o bienes, lo que, aunque no se conocía explícitamente como una técnica especializada en mecanismos alternos de solución de controversias, ayudaba a que las partes evitaran todo un procedimiento costoso y tedioso como son los juicios de carácter familiar. 
Consecuentemente, por primera vez en México, la mediación familiar es introducida en 1986, a través de lo que se conoce como audiencia previa y de conciliación, pero posteriormente, el Consejo de la Judicatura Federal emitió una serie de acuerdos tal como el 16-26/2003, donde se aprobó la ejecución de etapas de un proyecto de justicia alternativa, que posteriormente a través del acuerdo 1947/2003 creó el Centro de Justicia Alternativa del Tribunal Superior de Justicia del Distrito Federal, así como el programa de Soluciones alternativas de controversias y las reglas de operación.

Así, este Centro de Justicia Alternativa en la Ciudad de México, como menciona Gómez (2012) no contaba con una ley orgánica, pero posteriormente se emitieron leyes para regular la materia como la ley de Justicia Alternativa del Tribunal Superior de Justicia del Distrito Federal, la cual se publicó en la Gaceta Oficial del Distrito Federal el 20 de diciembre de 2007, entrando en Vigor el 8 de marzo de 2008. De manera que, los medios alternativos ya empezaban a hacer eco de su efectividad hasta elevarse a rango constitucional en el artículo 17 constitucional a través de la reforma de 2008. Por un lado, Gómez Frode (2012) menciona que los primeros asuntos en resolverse sobre conflictos familiares en el Distrito Federal (hoy Ciudad de México), fueron de la siguiente manera:

Figura 1. Gráfica del tipo de asuntos familiares radicados del 1o. de septiembre de 2003 al 15 de diciembre de 2004

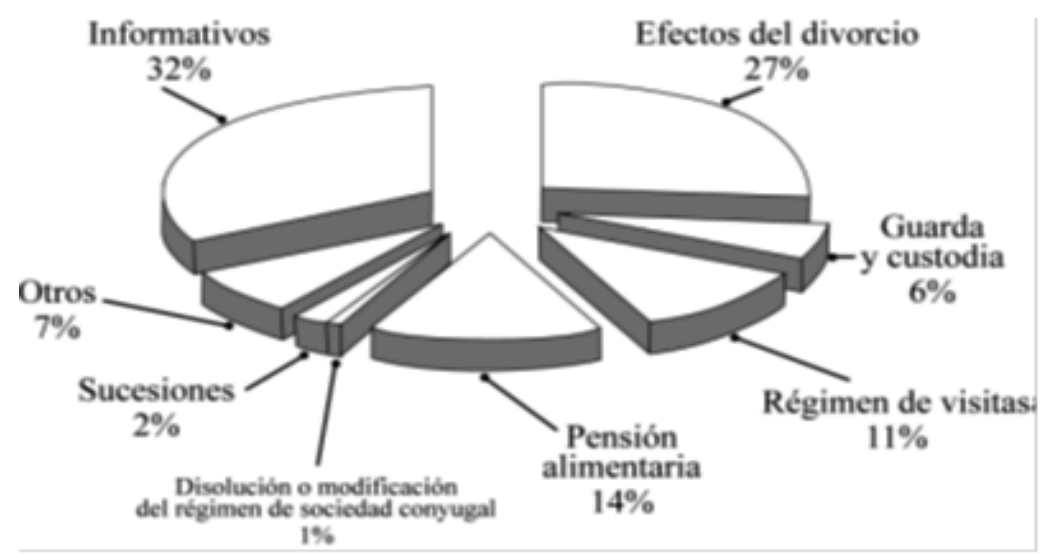

Fuente: Gómez Frode (2012). 
De tal manera, se puede ver como los comienzos de la mediación familiar en México empezaban paulatinamente a dar resultados, sin embargo, a pesar de los bajos porcentajes que presentaban, se reflejaron grandes cambios en la manera de manejar los conflictos en esta materia.

En ese sentido, en septiembre de 2003 -en lo que hoy es la ciudad de México-, se establecieron órganos como el Centro de Justicia Alternativa, el cual se encuentra bajo la dependencia del Tribunal Superior de Justicia del Distrito Federal, órgano que no contaba con una ley orgánica en ese entonces, sin embargo, de manera provisional se elaboró un acuerdo donde se estableció la normatividad para su operatividad. Por consiguiente, empezaron a transcurrir varios años para que se diera origen a la Ley de Justicia Alternativa del Distrito Federal, publicada en la gaceta oficial del Distrito Federal de 2007, entrando en vigor hasta el 2008.

En ese tiempo, esto era una novedad de que estos mecanismos se empezaran implementar antes de acudir hasta las instancias judiciales, cabe señalar la recepción positiva que tuvieron estos estos métodos alternativos por parte de la población capitalina, dándose testimonios del personal que había trabajado en el Centro de Justicia Alternativa quienes comentaron que se había dado soluciones negociadas a sus conflictos, de igual mencionaron los cambios personales y las relaciones personales en ellos mismos. (Díaz, p.730)

Si bien, los mecanismos alternos de solución de controversias te dan otro panorama de lo que son y de qué manera pueden resolverse los conflictos por una vía alternativa, sin necesidad de llegar a las instancias judiciales que suelen ser tediosas y agravan más las relaciones entre las personas. Las ventajas que traen consigo la implementación de estos mecanismos es efecto, que se mejoren las relaciones que hay entre las personas, lo que en el caso de la mediación familiar, hace que los mismos profesionales de la mediación, mejoren sus conductas conforme a la práctica de estos mecanismos.

¿Por qué mencionan que se empezaron a ver los cambios personales y las relaciones personales entre ellos mismos? Si bien es cierto el profesional de la medi- 
ación tiene que ser una persona capacitada para poder resolver el conflicto entre las personas así como imparcial, no obstante, al utilizar herramientas como la escucha activa, y otros ejercicios de mediación, desarrollan la empatía y otros valores, dándose un cambio personal y mejorando las relaciones con las personas que se rodean.

Por consiguiente, otro de los estados que se dieron a la tarea de ponerse a la vanguardia con los mecanismos alternos de solución de controversias, fue el estado de Jalisco en el cual gestionó la tarea de implementar diversos foros de consulta ciudadana en diversos puntos de la entidad para el año 2004, participando en estos, la procuraduría general de justicia, la barra de abogados, juristas, académicos de universidades, con la finalidad de discutir la creación de una ley en la materia, además de que se le diera solución a los conflictos en materia civil, familiar, y algunos en materia penal, que posteriormente presentaron la iniciativa de un proyecto de Ley de Justicia Alternativa (Hernández y Casillas, 2015, p.123)

Posteriormente, en Jalisco se fueron actualizando respecto a la justicia alternativa, ya que con los trabajos a las reformas del artículo 56 de la Constitución Política de su estado, se dieron avances en crear un órgano especializado en la impartición de justicia alternativa. En ese sentido, se crean las primeras sesiones en las cuales asignaron como directores a los Licenciados Jorge García Domínguez y Oscar Magallanes de la Rosa, en las direcciones de métodos alternativos y validación, así como director de acreditación, certificación, y evaluación.

De manera que, Jalisco se puede considerar un estado avanzado en la materia que cuenta con la debida acreditación, certificación y evaluación para todo aquel candidato que aspire a obtener una vacante en el ejercicio de la mediación.

Por otro lado, los avances que presenta la mediación familiar en sus primeros inicios se puede ver en el caso de Aguascalientes. Durante el periodo de 2007 a 2011 se reflejan la serie de convenios terminados a través de estos mecanismos, así el Centro de Mediación y Conciliación del Tribunal Superior de Justicia del Estado de Aguascalientes, se empezaron a resolver asuntos familiares a partir del 
año 2007 acrecentándose de la siguiente manera: en 2007 en el Centro de Mediación y Conciliación atendieron 225\% más asuntos que en 2006, y se signaron 780 convenios de mediación de los cuales 61 eran familiares, por consiguiente en 2008 de los 35666 juicios nuevos, 7950 fueron familiares, no obstante el número de convenios que se elaboraron fueron 1253 en esta materia.

Posteriormente, en 2009 fueron aumentando los juicios que resultaban en un total de 38,344, de los 7894 eran familiares, lográndose 2856 acuerdos de los cuales 1398 acuerdos eran en materia familiar. En 2010 hubo 3779 asuntos sometidos a mediación familiar, de los cuales se logró 1396 acuerdos en el mismo campo.

Es importante mencionar que desde la reforma al artículo 17 constitucional en junio de 2008, la mayoría de los estados se empezaron a actualizar en materia familiar, de manera que las entidades federativas así como Aguascalientes, fueron incrementando de manera paulatina sus asuntos familiares por año, esto quiere decir que la población empezó a considerar los mecanismos alternos de solución de controversias como una salida alterna con un procedimiento eficaz y sencillo, a pesar de que fueron incrementándose los juicios, de igual manera empezaron a aumentar los asuntos en esta especialidad así como el número de convenios.

Por un lado, otros estados de la república ya se habían adelantado respecto a la implementación de estos mecanismos como es el caso de Colima desde 2003, Coahuila 2005, Guanajuato desde 2003, Nuevo León en 2005 y Oaxaca desde 2004 entre otros.

En el caso de Nuevo León, ya se contemplaba desde enero de 2005, mencionándose los elementos más importantes de la mediación como la obligatoriedad en materia civil y familiar, el uso de la cláusula compromisoria y el acuerdo compromisorio, las causales de nulidad de convenio entre otras. Cabe señalar que la ley se reformó el 28 de Junio de 2017, donde es claro que en los procesos contenciosos familiares, la mediación se debe agotar con la finalidad de garantizar los derechos de los menores, incapacitados y los derechos inherentes que provienen del matrimonio (art.43) 
De manera que, el Estado de Nuevo León se ha puesto a la vanguardia, dado que ha establecido una obligación de poder agotar los mecanismos alternos de solución controversias en materia familiar antes de entrar en un juicio de ese carácter. De modo que, esta Entidad Federativa tiene más experiencia en la implementación de la justicia alternativa, lo que se puede reflejar en su reforma, estableciendo un deber de los servidores públicos y del juez en el auto de radicación, de considerar previamente los mecanismos.

Sin embargo, en la actualidad, González (2020) elabora una lista sobre los estados que contemplan o no expresamente en cada una de sus leyes, la mediación familiar:

Tabla 1.Entidades federativas que expresan la mediación familiar en sus legislaciones

\begin{tabular}{|c|c|}
\hline \multicolumn{2}{|c|}{ Entidades federativas que expresan la mediación familiar en sus legislaciones } \\
\hline $\begin{array}{l}\text { En casos familiares se requiere una declaración } \\
\text { expresa de la inexistencia de violencia familiar en el } \\
\text { conflicto }\end{array}$ & Aguascalientes \\
\hline $\begin{array}{l}\text { Contempla a la materia familiar separa de la civil } \\
\text { pero no expresamente la mediación en esta materia. }\end{array}$ & $\begin{array}{l}\text { Baja califomia sur, Estado de México, Jalisco } \\
\text { Campeche, Nayanit, Yucatán, San Luis Potosi, } \\
\text { Chiapas, Ciudad de México, Chihuahua, Colima, } \\
\text { Ciudad de México }\end{array}$ \\
\hline $\begin{array}{l}\text { No la contempla expresamente, pero la violencia } \\
\text { familiar con menores se contempla en la ley de } \\
\text { justicia para adolescentes }\end{array}$ & Coahuila \\
\hline $\begin{array}{l}\text { La violencia familiar es una causa del proceso de } \\
\text { teminación de la mediación }\end{array}$ & Hidalgo, Oaxaca \\
\hline No se contempla expresamente la mediación familiar & $\begin{array}{l}\text { Michoacán, Sonora, Baja Califomia, Tabasco } \\
\text { Puebla, Morelos, Tamaulipas, Guerrero } \\
\text { Guanajuato, Querétaro, Veracruz }\end{array}$ \\
\hline $\begin{array}{l}\text { Los acuerdos hechos por instituciones privadas y } \\
\text { posteriormente se registren, no constituirán cosa } \\
\text { juzgada }\end{array}$ & Nuevo León \\
\hline \multirow{2}{*}{$\begin{array}{l}\text { En asuntos familiares no se permite la representación } \\
\text { legal, ya que son asuntos personales. }\end{array}$} & Quintana Roo \\
\hline & Durango \\
\hline Si la contempla expresamente & Sinaloa \\
\hline $\begin{array}{l}\text { Se establecen expresamente los supuestos de } \\
\text { mediabilidad en materia familiar }\end{array}$ & Tlaxcala \\
\hline
\end{tabular}

Fuente: González Martin (2020).

Por un lado, se puede ver que tan solo tres estados hasta la actualidad contem- 
plan la negativa de procedencia para la mediación en casos de violencia familiar, aunque hay autores quienes consideran la posibilidad de llevar a cabo este tipo de mecanismos alternos contemplando bases especializadas para la reconstrucción de este problema.

La posibilidad de una mediación familiar aunque no se encuentre expresamente en los estados de la república, siempre es posible, dado que los órganos ya se encuentran instaurados, o bien existen legislaciones que tácitamente abren la posibilidad de acudir a lo que se conoce como justicia alternativa. Sin embargo, aunque esto no se encuentre contemplado dentro de las legislaciones, el derecho a los mecanismos alternos ya se considera un derecho humano universal de lo cual se infiere que toda persona tiene el derecho de solicitarlos en las instancias judiciales.

Ahora bien, es interesante adentrarse como en la actualidad, el desarrollo de la mediación familiar se ha venido enfocando durante los últimos 4 años, lo que veremos a partir de las estadísticas que el Instituto Nacional de Estadística y Geografía (INEGI) ha elaborado en sus informes respecto a los avances en los Censos de Impartición de Justicia Estatal por año.

En ese sentido, el Instituto Nacional de Estadística y Geografía (INEGI, 2016) indica que durante el año 2015 se recibieron 164244 solicitudes de acceso a través de los mecanismos alternos de solución de conflictos, donde 150, 475 fueron procedentes, mientras que 13769 fueron desechadas. Asimismo, el 84.2\% de las solicitudes fue a través de la mediación y el $8 \%$ fueron de conciliación, de manera que en los expedientes abiertos el $39.5 \%$ fueron en materia familiar (54515) 30 $\%$ en materia civil, $11.7 \%$ en materia mercantil (16 110) y $9.4 \%$ en penal (13 034), sin embargo, el resto de las materias forman 9.4 por ciento (13 027).

Seguidamente, durante el año 2016, el Instituto Nacional de Estadística y Geografía (INEGI, 2017) en su Censo Nacional de Impartición de Justicia 2017, menciono que ingresaron 156899 asuntos en los centros de justicia alternativa de los cuales se presenta a continuación: 
Figura 2. Número de asuntos que entraron a través de Justicia alternativa durante 2016

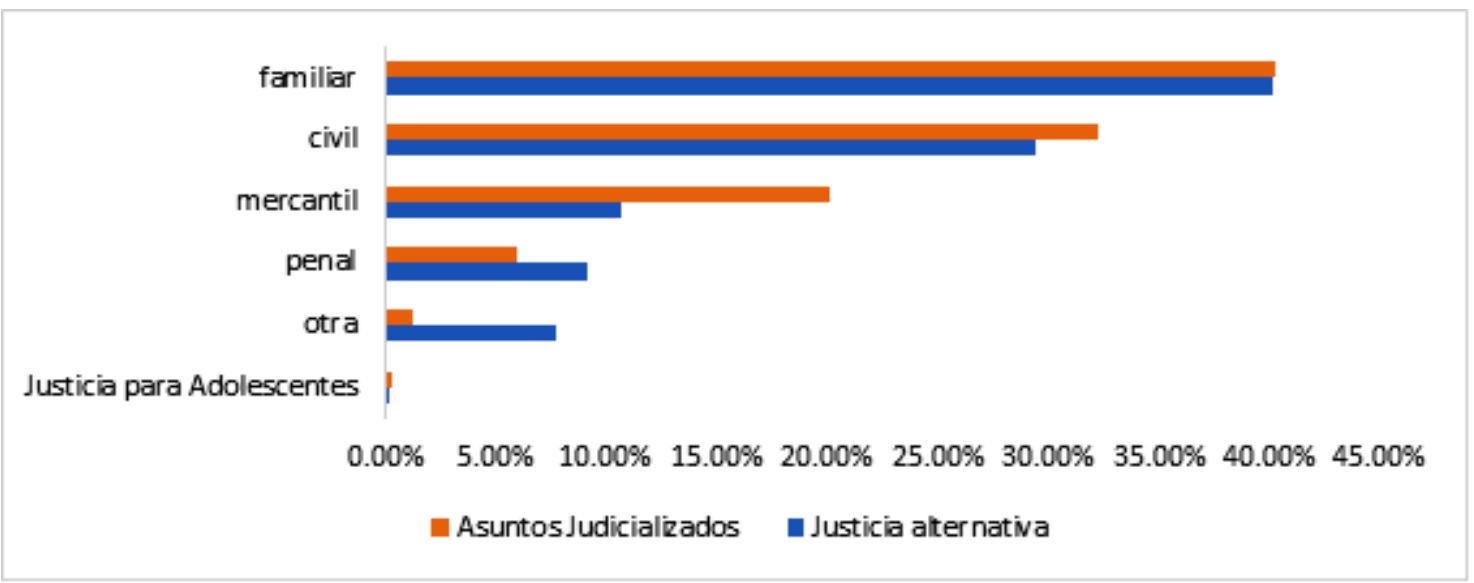

Fuente: Censo Nacional de Impartición de Justicia Estatal - INEGI (2017).

Por otro lado, durante el año 2017, entraron un total de 158120 asuntos de conflictos familiares a los centros de justicia alternativa o justicia especializada, por lo que se puede notar el crecimiento en los asuntos que se canalizan en las diferentes áreas, así el número de casos donde incremento fue nuevamente el área de mediación familiar a nivel nacional. Por lo tanto, se muestra del total de 158120 asuntos, el porcentaje de casos por materia que entraron a los centros de justicia alternativa

Figura 3. Asuntos ingresados por Materia a los centros de justicia especializado representados por porcentaje

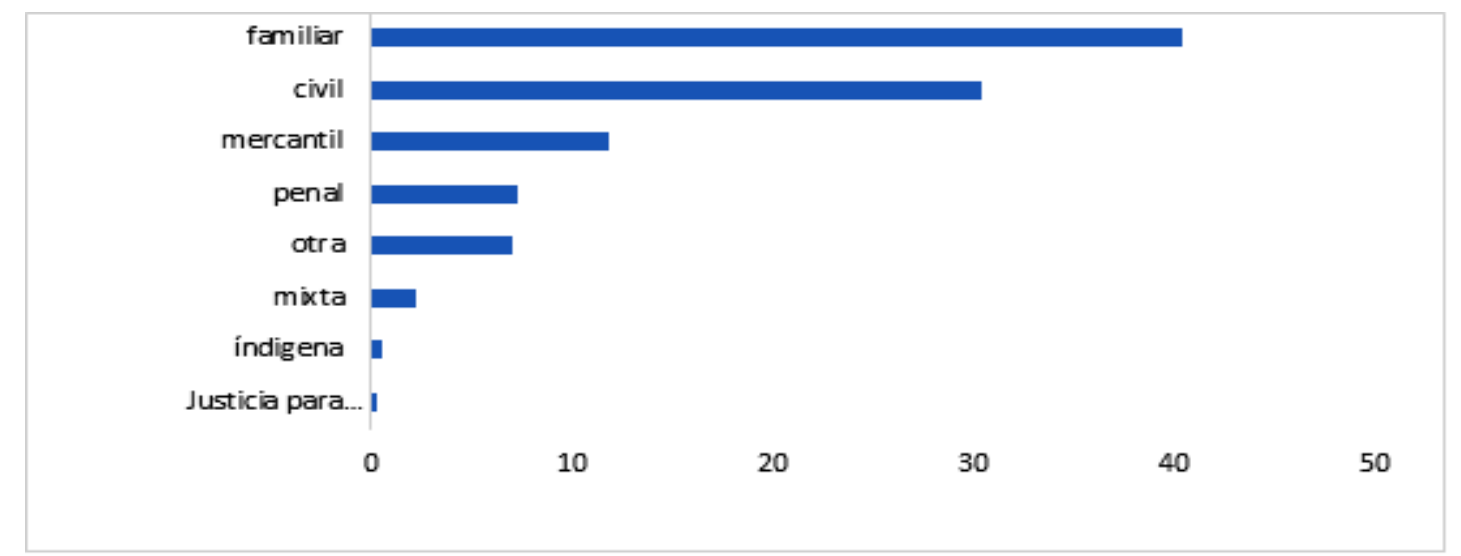

Fuente: Censo Nacional de Impartición de Justicia Estatal - INEGI (2018). 
Por otro lado, el Censo Nacional de Impartición de Justicia Estatal 2019 (INEGI) informó que durante el año 2018, los poderes judiciales de cada entidad federativa arrojaron un total de 176,682 expedientes que ingresaron a los órganos de justicia alternativa quedando distribuidos por materia de la siguiente manera:

Figura 4.Asuntos por materia en los centros de justicia alternativa

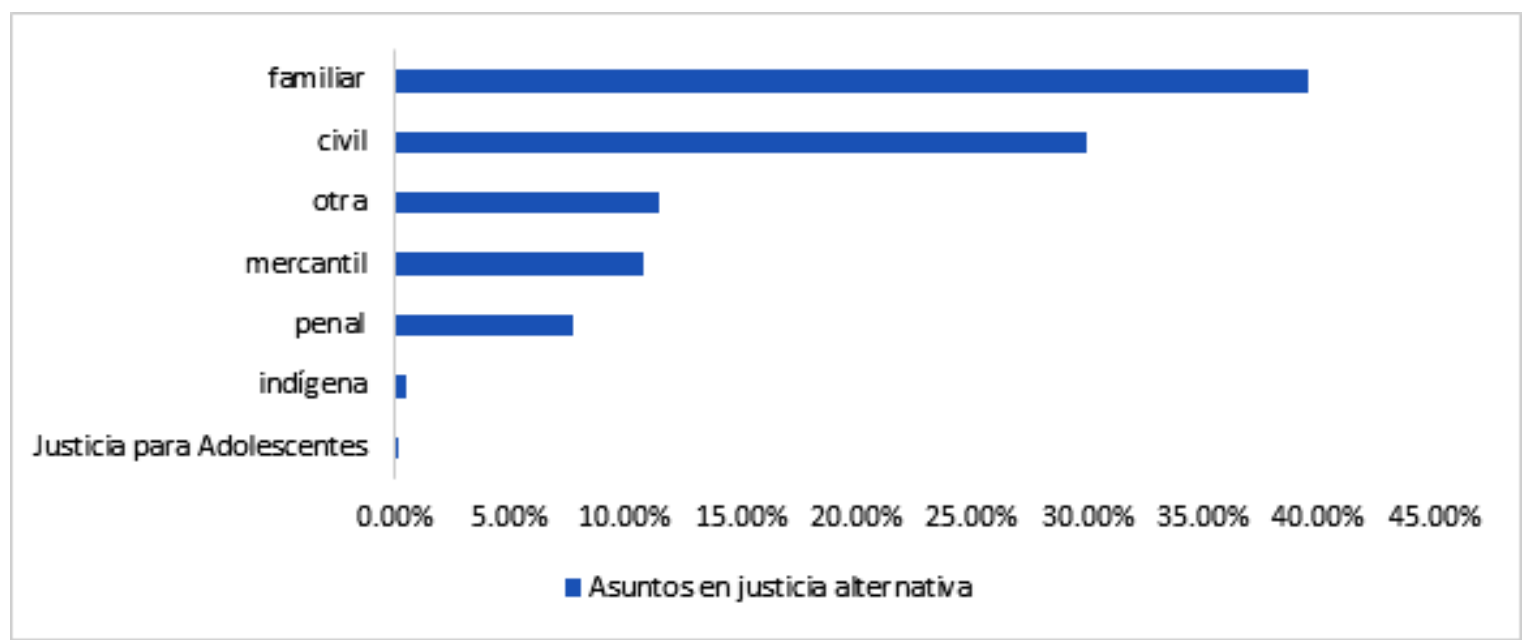

Fuente: Censo Nacional de Impartición de Justicia Estatal - INEGI (2017).

De igual manera, se puede ver que cada año los casos de mediación familiar a nivel nacional han venido creciendo, lo que arroja resultados positivos en el número de crecimiento de este modelo de justicia que se ofrece en la modalidad extrajudicial e intrajudicial que se analizó en epígrafes anteriores.

Los resultados positivos en relación a la consolidación de la mediación familiar como mecanismo alterno de solución de controversias, también se puede notar en el número de expedientes concluidos dentro del último censo de impartición de justicia estatal del INEGI 2019 analizado anteriormente, estableciendo que en ese año de los 176,682 expedientes ingresados a los centros de justicia alternativa en general, se concluyeron 158, 748 solucionándose a través de acuerdos reparatorios -en el caso de la materia penal- asimismo, se terminaron de forma anticipada sin lograr un acuerdo, y de igual manera se dieron como concluidos por cualquier otra causa (INEGI 2019) lo que sin duda alguna es un gran avance en la conclusión de los conflictos sometidos a través de este modelo de impartición de 
justicia, incluyéndose la mediación familiar.

De tal manera, la mediación familiar en México ha llegado a tener un gran avance respecto a la forma de desarrollo y el número de casos abiertos y concluidos por lo que es un gran indicador de que los mecanismos alternos de solución de controversias son la mejor opción para resolver sus conflictos familiares, sin la necesidad de llegar a la parte jurisdiccional.

Por un lado, lo que se debe anticipar es que en materia familiar todavía falta mucho por hacer, eso se debe principalmente al número de asuntos que ingresan a las salas de mediación, si bien es cierto, no todos los asuntos logran resolverse, se debe recordar que aunque las estadísticas arrojen un gran volumen de asuntos en los centros de justicia alternativa, los acuerdos que se logran siguen siendo muy bajos, las razones por las que sucede esto, se debe a causa de muchos factores, como por ejemplo la falta de aptitud o desconocimiento del desarrollo de los mecanismos alternos por parte de mediadores, o bien, un incorrecto desarrollo de la mediación por parte del profesional.

\section{3.-MÉTODO}

En el presente trabajo se hizo un diseño no experimental, donde se elaboró una revisión bibliográfica de la literatura especializada en mecanismos alternos de solución de controversias en materia familiar, por lo que también se hizo una exploración a las páginas especializadas en estadísticas como el Censo Nacional de Impartición de Justicia Estatal donde se analizan las estadísticas de la justicia alternativa en conflictos familiares. Asimismo, este estudio aborda un método de carácter cualitativo donde se estudian cada una de las estadísticas mencionadas relativas a los avances que se han tenido a nivel nacional en mediación familiar, por lo que también se analiza cada uno de los gráficos que se ilustran.

La muestra o población que se consideró en el presente trabajo, se enfocó en las entidades federativas que regulan -en sus respectivos poderes judiciales-, la mediación en materia familiar, por lo que se hizo una revisión de sus respectivas leyes, así como sus casos familiares que se encuentran sometidos en los órganos 
especializados en justicia alternativa.

Por un lado, la presente investigación inicia con análisis pormenorizado de los conflictos familiares, después sobre los conceptos de mediación familiar, los principios en la justicia alternativa, y finalmente el análisis de las leyes y las estadísticas.

Para poder analizar cómo se estructura la mediación familiar es necesario adentrarse dentro de la literatura especializada que se han encargado de construir conceptos específicos sobre este mecanismo, así como los principios la rigen.

\section{4.-CONCLUSIONES}

En el presente trabajo se manejaron conceptos relativos a los conflictos familiares y la mediación familiar, los principios que rigen los conflictos familiares, un ejemplo de este último es el de confidencialidad, donde se considera como delicada la información que se vierte dentro de la mediación, dado que es de sumo cuidado para la partes que se encuentran inmiscuidos dentro de los procedimientos, de tal manera se considera el más importante para el desarrollo de los principios.

Asimismo, aunque no se haya llegado a un concepto unánime en conflictos familiares, los mayoría de los autores están de acuerdo que dentro de este tipo de controversias se encuentran implicados casos de herencia, relaciones conyugales, patria potestad, alimentos, por lo que a nuestra consideración se necesita de expertos en la materia familiar para que puedan entender a las partes, asimismo se requiere la especialización de mediadores en esta área, para entender las necesidades e intereses de las personas que se someten a este tipo de procedimientos.

Por otro lado, la mediación familiar ha tenido muchos avances respecto a la forma de darle impulso en la solución de los conflictos, sin embargo, cada vez son más el volumen de casos que se resuelven en las entidades federativas hasta la actualidad a través de la justicia alternativa en diferentes materias. Se reitera que aunque haya un gran cúmulo de asuntos dentro de los órganos especializados de mediación, los convenios que se hacen, siguen siendo bajos, se debe ver las razones 
por las que sucede este fenómeno, enfocándose en el personal que se encuentran dentro de estas áreas.

Sin embargo, se debe considerar que para este tipo de solución alterna de conflictos crezca, la capacitación es necesaria y no solo a los que aspiran a cargo de mediadores, se necesita que todo el personal de un juzgado familiar, desde los oficiales administrativos, hasta los jueces del fuero común se capaciten respecto a la mediación, de manera que, con la debida formación en justicia alternativa harán que en las primeras audiencias los jueces o el personal informen a las partes de que tratan estos procedimientos.

Si bien es cierto, en los acuerdo de inicio se les hace saber a las partes la posibilidad de acudir a los mecanismos alternos de solución de controversias, pero no se les hace de su conocimiento de manera profunda de que tratan, como se desarrollan, que conflictos pueden ser sometidos ante los mecanismos alternos de solución de controversias, en que tiempo pueden resolverse, las falta de conocimiento por parte del personal produce que los mecanismos no se le den la debida importancia que tienen dentro del procedimiento judicial, así como antes de instaurarlo. Asimismo, al darle la información debida a las partes, en las audiencias podrán conocer este proceso y el número de juicios decrecerá, con las posibilidades de éxito en el desarrollo de estos procesos de justicia alternativa.

A raíz de la reforma de 2008 al artículo 17 constitucional, todas las entidades federativas ya contemplan a la mediación como una opción para resolver los conflictos de carácter familiar, son pocos los estados que la contemplan expresamente, otros la hacen obligatoria de manera previa a los juicios, o bien otros la establecen expresamente en sus legislaciones. Sin embargo, los estados deben realizar estudios en entidades que conserven más experiencia en el medio de la justicia alternativa familiar, dado que en el caso de Nuevo León ya se lleva un adelanto en esta materia, o en ciudad de México, de modo que, son modelos a seguir para que se puedan considerar políticas públicas o reformas a sus legislaciones. 


\section{REFERENCIAS}

De la Rosa, F.E. (2010) Régimen Europeo de la Resolución Electrónica de Litigios (ODR) en la contratación Internacional de Consumo, en Garrido Carrillo, Francisco (Coord.) Valencia; Mediación y Arbitraje de Consumo Una perspectiva española, europea y comparada. (pp.165-223) Valencia. Tirant lo Blanch.

Díaz, Miguel Luis (2009) “¿artículo 17 de la Constitución como opción al orden jurídico?”, Anuario Mexicano de Derecho Internacional, México, enero, 2009, Volumen 9. Pp.707-740.

Franco Conforti O.D. (2018) La mediación, en Pérez Sauceda José Benito, Franco Conforti Oscar D y Zaragoza Huerta, D. Mediación Temas Selectos, (pp.1337) Ciudad de México: Editorial Tirant lo Blanch.

Funquen Alvarado, M. E. Los conflictos y las formas alternativas de resolución, Tabula Rasa. Revista de Humanidades (1), 265-278

Gómez Frode Carina X (2012) la mediación en materia familiar. Por la generación de una cultura de paz y no de conflicto. Revista de Derecho Privado, (Edición Especial), 165-179.

González Martin, N. (2020) Los medios alternos de solución de Conflictos en la legislación mexicana, en Sánchez Castañeda A, Márquez Gómez Daniel, Camarillo Cruz Beatriz, (Coords.) en Desafíos de los medios alternativos de solución de controversias en el derecho mexicano contemporáneo, México: Universidad Nacional Autónoma de México, defensoría de los derechos universitario.

Gorjón Gómez. F.J. (2017) "Mediación su valor intangible y efectos operativos "Una visión integradora de los métodos alternos de solución de conflictos" Ciudad de México: Editorial Tirant lo Blanch.

Gorjón Gómez, F.J. y Steele Garza J. G. (2012) Métodos Alternativos de Solución de Conflicto, México: Editorial Oxford. 
Gorjón Gómez, F. J. y Vázquez Gutiérrez, R.L. (2015) métodos alternos de solución de conflictos y su protagonismo en el nuevo contexto legal mexicano, retos y perspectivas, en Arellano Hernández F.P. y Cabello Tijerina P. A. (coords.) Retos y perspectivas de los MASC en México, (p.8-37) México, Editorial Tirant lo Blanch.

Iglesias Ortuño E. (2018). Competencias para mediación en conflictos sociales, Ciudad de México: Editorial Tirant lo Blanch

Instituto Nacional de Estadística y Geografía (2016). Censo de Impartición de Justicia Estatal 2016. https://www.inegi.org.mx/programas/cnije/2016/

Instituto Nacional de Estadística y Geografía (2017). Censo de Impartición de Justicia Estatal 2017. https://www.inegi.org.mx/programas/cnije/2017/

Instituto Nacional de Estadística y Geografía (2018). Censo de Impartición de Justicia Estatal 2018. https://www.inegi.org.mx/programas/cnije/2018/

Instituto Nacional de Estadística y Geografía (2019). Censo de Impartición de Justicia Estatal, 2019. https://www.inegi.org.mx/programas/cnije/2019/

Martínez Tenorio, J. E. (2019). Derechos humanos, género, familia y sus cambios en el derecho de familia en México en Guzmán Avalos, A. y Valdés Martínez, M. C. Ciudad de México: Tirant lo Blanch.

Ortuño Muñoz, P. (2000). La mediación familiar intrajudicial. Un reto para la práctica del derecho de familia. Revista de Derecho de Familia: doctrina, jurisprudencia, legislación, (7), 43-65

Perrone, L. (marzo de 1999). Seminario de mediación familiar. Universidad Pontificia de Salamanca, Instituto Superior de Ciencias de la Familia, Salamanca.Ponce Alburqueque, J. (2017). Familia, conflictos familiares y mediación. Madrid: Editorial Reus.

Rodríguez Llamas, S. (2010). La mediación familiar en España. Fundamento, Concepto y modelos jurídicos. Valencia: Editorial Tirant lo Blanch 
Pérez Contreras, M. (2008). Mediación familiar en el Distrito Federal. Un acercamiento al procedimiento y a su regulación. Boletín Mexicano de Derecho Comparado (60), 933-958

Serrano Pérez, D. (2015). Procuraduría Social del Estado de Jalisco: como agente pacificador Retos y Perspectivas de los MASC en México en Arellano Hernández, Francisca Patricia y Cabello Tijerina, Paris Alejandro (coords.) México: Editorial Tirant lo Blanch.

Valdivia Salas, B.I. (2019). Derechos humanos, género, familia y sus cambios en el derecho de familia, en Guzmán Avalos A. y Valdés Martínez M.C. Construcción del Derecho de Familia, (pp.163-178) Ciudad de México: Editorial Tirant lo Blanch. 